\title{
Dependence of the sizes of periosteal callus from treatment mode, age of patients and axial load on the limbs
}

\begin{abstract}
It was established that the periosteal callus appears regularly after the transfer of patients to the outpatient treatment mode, its dimensions depend on the stiffness of fixation of the fragments (micromotion more than $70 \mu \mathrm{m}$ per $10 \mathrm{~kg}$ of load), the duration of the fixation period and the age of the patients. The appearance of periosteal callus is a manifestation of the compensatory response of the body, contributing to the additional fixation of bone fragments and the stabilization of the age-related increase in the duration of the treatment period after 45 years. As the age of the corns of the humerus increases, the duration of the fixation period decreases.
\end{abstract}

The purpose of the study was to find out what caused the appearance of periosteal corn and an increase in the length of treatment according to Ilizarov for patients with fractures of limbs when they are transferred to an outpatient regimen.

Analyzed data from the study of the duration of the fixation period, micromotion of bone fragments during loading of the limb and the size of the periosteal corn in adult patients with closed fractures of the tibia during the Ilizarov treatment in the hospital and clinic (respectively 99 and 37 people), as well as in patients with diaphyseal fractures shoulder (38)

Keywords: transosseous osteosynthesis, bone fracture, periosteal callus

\section{Introduction}

Periosteal reaction occurs in the treatment of bone fractures after injuries with damage to the bone marrow, with insufficiently accurate reposition of the ends of the fragments and their unreliable fixation with increasing functional load on the limb. ${ }^{1-3}$ In terms of adherence to the principles of treatment of patients according to the Ilizarov method, the periosteal callus is practically absent in patients, bone fusion with closed spiral fractures of the shoulder and tibia occurs on average $54-58$ days. $^{4}$

It is known that the duration of treatment of fractures increases in patients with increasing age. ${ }^{3,5}$ For every 10 years of life, the duration of the fixation period in Ilizarov treatment of closed spiral fractures of the bones of the leg in stationary conditions increases by 2 days, with comminuted - by 3.3 days.

It was assumed that the transfer of patients with closed shin fractures to an outpatient regimen, carried out in recent decades, should lead to an increase in the micromobility of bone fragments with a functional load on the limb.

The dynamization of the "apparatus-limb" system within the limits of rigidity of fixation of at least $7 \mathrm{~N} * \mathrm{~m} /$ hail should have a stimulating effect on the blood supply to the limb and the rate of corn formation..$^{6-11}$ However, in fact, when transferring treatment of patients to an outpatient regimen, it was not a decrease, but a significant increase in the duration of the fixation period, ${ }^{5}$ which may be associated with a weakening of medical control over the fixation mode and with an excessive increase in the micromotion of bone fragments.

The aim of the work was to find out which values of fixation rigidity are optimal, how age of patients affects periosteal callus and treatment time, and how increases in functional load, which is absent in the treatment of patients with fractures of the humerus, affect the formation of periosteum.
Volume 6 Issue I - 2019

\section{Schurov VA, Melnikova LV \\ The Russian Scientific Center "Restorative Traumatology and Orthopedics", Russia}

Correspondence: Schurov VA, Doctor of medical Sciences, Professor, Chief scientific, llizarov Research Center for Rehabilitating Traumatology and Orthopaedics, Kurgan, Russia, Tel +7919 571 4942, Email shchurovland@mail.ru

Received: December 13, 20I8 | Published: February 26, 2019

\section{Material and research methods}

The survey data of 99 patients, mostly male, with closed fractures of the bones of the tibia aged from 17 to 63 years who were treated by Ilizarov in the hospital of the RSC "RTO" clinic (group 1) were analyzed in comparison with a similar group of patients (37 people) which, 2 weeks after osteosynthesis, were transferred to an outpatient treatment regimen compared to 38 patients treated with Ilizarov in the same regimen with closed fractures of the humerus diaphysis.

In all patients using radiographs at the end of the fixation period, the area of the shadow of the periosteal callus in the frontal plane was calculated using a planimetric approach. In the process of fixation, the micromobility of the tibial fragments was regularly determined with a dosed stepwise increasing axial load of $10 \mathrm{kGs}$ of the injured limb. ${ }^{11}$ When using a strain gauge and a B7-73/1 voltmeter (Belarus), a change in the strain gauge signal from a pre-tensioned spring was recorded, making it possible to determine the change in distance between the spokes coming out of the bone above and below the fracture zone with an accuracy of $1 \mu \mathrm{m}$.

Statistical processing of the research results was carried out using the Microsoft Exell-2010 data analysis package. When analyzing the dynamics of changes in indicators, the methods of correlation and linear regression analysis were used (with the designation of the linear correlation coefficient $r$ or index of determination R2). To assess the statistical significance of the differences between the results of the two samples, Student's t-test was used.

\section{Results and discussion}

Compared with the indicators of patients in group 1, the duration of the fixation of bone fragments in patients treated on an outpatient basis increased from $59 \pm 2$ to $94 \pm 7$ days $(p \leq 0.001)$. The crosssectional area of the tibial periosteal callus in patients of the 1st group 
was respectively $45 \pm 15$ (in $20 \%$ of cases it was not determined), in patients treated on an outpatient basis, the rate reached $213 \pm 25 \mathrm{~mm}^{2}$ $(\mathrm{p} \leq 0.001)$ (Figure $1 \& 2)$.

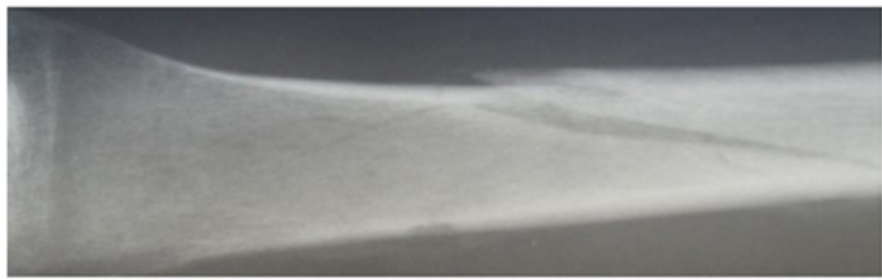

Figure I Radiograph of the tibial bone of the patient K-th -3| year, after the end of inpatient treatment. The term of fixation is 50 days, the area of periosteal corn is $-25 \mathrm{~mm}^{2}$.
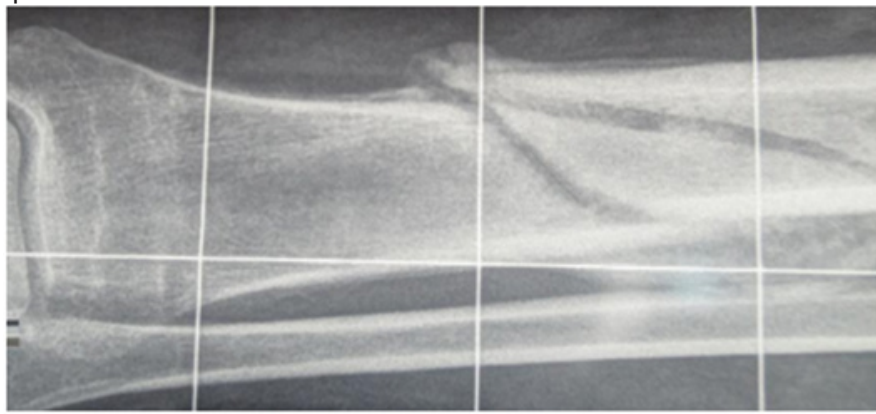

Figure 2 Radiograph of b-go G-va 29 years, after outpatient treatment, the term of fixation 120 days, the area of periosteal corn $1080 \mathrm{~mm}^{2}$.

In patients of the 1st group, a linear correlation was found between the micromobility of bone fragments $(\mathrm{L}, \mu \mathrm{m})$ after osteosynthesis and the duration of the fixation period ( $\mathrm{T}$, days): $\mathrm{T}=0.12 * \mathrm{~L}+51.36$; $\mathrm{R}^{2}=0.877$. The smaller was the mobility index, determined by the accuracy of reposition and stiffness of fixation of fragments of the tibia, the faster the adhesion of the bone occurred.

While in the treatment of patients with fractures of the bones of the lower leg in both groups, the micromotion of the ends of fragments steadily decreased in inpatient conditions, then after the transfer of patients of the 2nd group to outpatient treatment, there was a period of increase in this indicator (Figure 3).

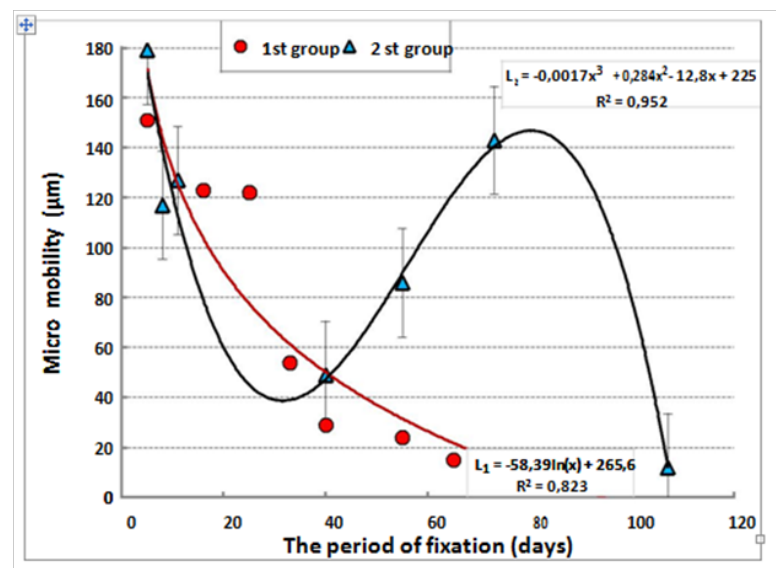

Figure 3 Dynamics of micromotion of bone fragments in the treatment of patients with injuries of the lower leg of the Ist and 2 nd groups.

A non-linear relationship was found between the values of the micromotion of bone fragments and the size of the periosteal corn. With an increase in patients of the 2 nd group of the micromobility of fragments up to $30 \mu \mathrm{m}$, a reduction in the size of the callus was observed. Such micromobility values are favorable for reparative regeneration. Moreover, in modern fixation systems, various techniques are used to achieve the effect of dynamization of bone fragments. ${ }^{6,79}$

However, in patients with indicators of micromotion more than 70 microns, indicating insufficiently rigid fixation of bone fragments, for example, with comminuted fractures, large sizes of periosteal corns were observed (Figure 4).

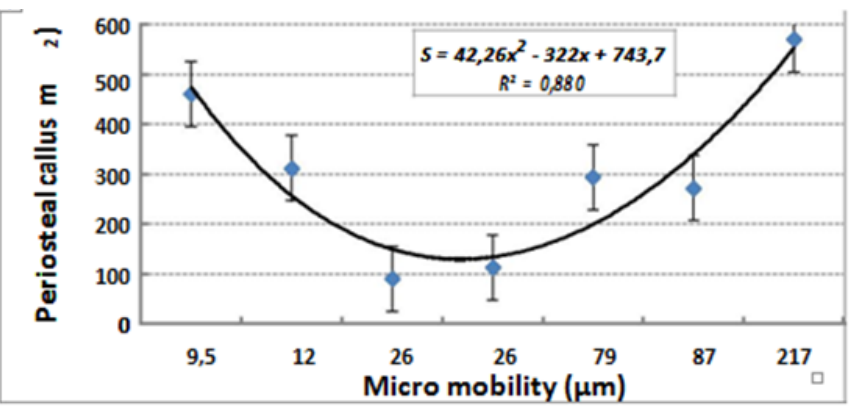

Figure 4 Interrelation of micromotion of bone fragments and size of periosteal callus.

The size of the bone callus of the tibia was dependent on the duration of the fixation period (Figure 5). Especially significantly, they increased in the first four months of the treatment period.

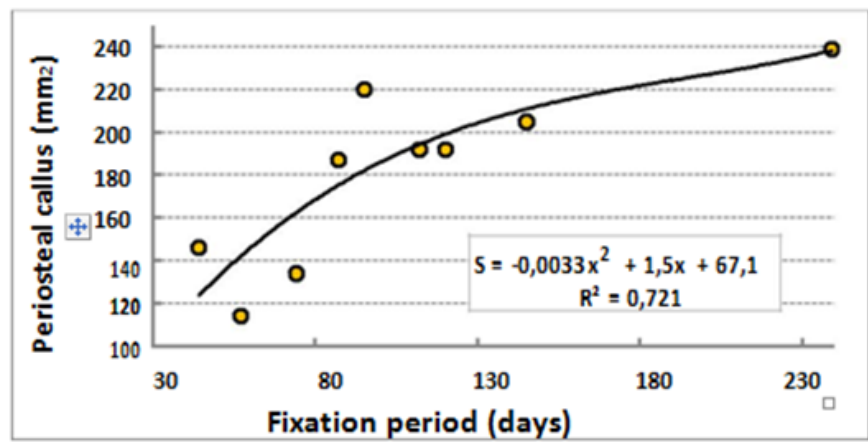

Figure 5 Dynamics of the size of the periosteal corns of the tibia in the process of fixation in patients of the $2^{\text {nd }}$ group.

With increasing age of patients from 7 to 60 years, the value of periosteal callus became larger. And only in patients older than 70 years, the size of periosteal callus began to decline (Figure 6).

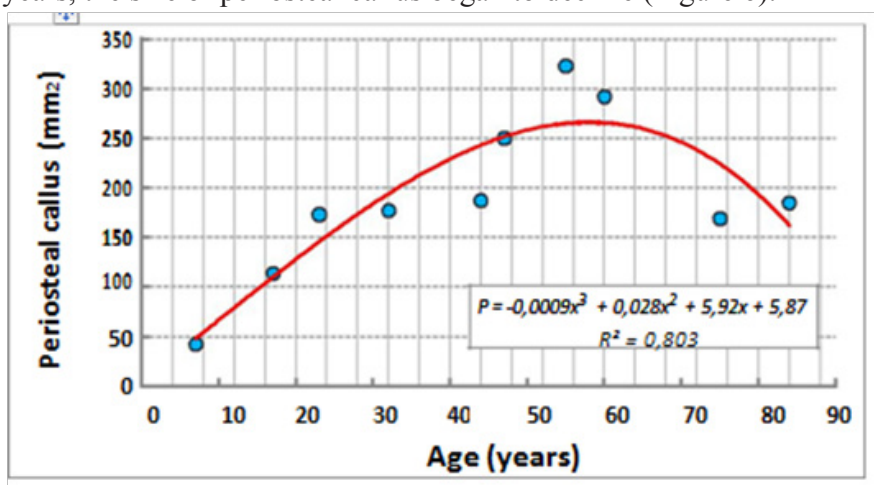

Figure 6 Age-related dynamics of the size of periosteal callus in fractures of the bones of the leg in patients of the 2 nd group.

The timing of fixation of bone fragments also increased with increasing age of the patients. The increase in the duration of 
treatment is especially significant in the first $25-45$ years of life, when body weight and bone strength become higher, for which damage it is necessary to apply more force. However, in the next 20 years of life, the fixation time was reduced (Figure 7). It was during this period of life that the most significant increase in the size of periosteal callus was observed (Figure 6).

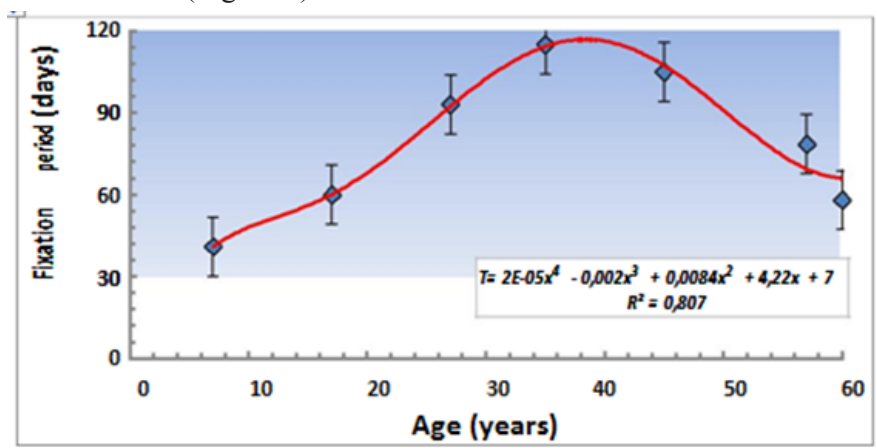

Figure 7 Age dynamics of the duration of the fixation period in patients of the $2^{\text {nd }}$ group.

A distinctive feature of patients with a fracture of the humerus was the fact that they did not have a period of increasing micromobility of bone fragments during outpatient treatment (Figure 8). The average size of periosteal callus was $153 \pm 16 \mathrm{~cm}^{2}$.

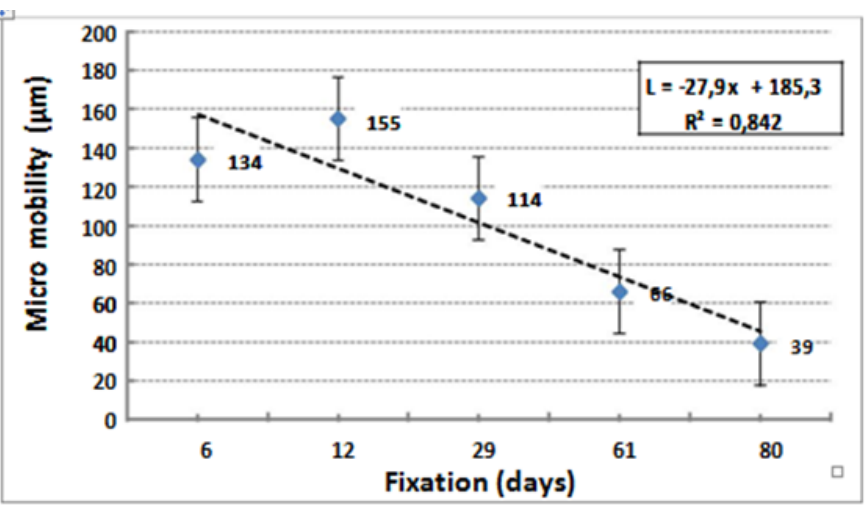

Figure 8 Dynamics of micromotion of bone fragments of the humerus in the treatment of patients on an outpatient basis.

The size of the cross-sectional area of the corn was smaller than the size of the corn of the tibia, but the difference is comparable to the difference in the diameter of the diaphyseal part of these bones $(25 \pm 0.8$ and $18 \pm 0.8 \mathrm{~mm})$. The duration of the fixation period reached an average of $82 \pm 3.4$ days.

The inverse relationship between the indicators of the duration of the fixation period and the size of the periosteal regenerate (Figure 9) revealed in patients of the 3rd group confirms the assumption that the formation and increase in the size of the periosteal corns is a factor contributing to the increase in the fixation of bone fragments and a reduction in the duration of the fixation period.

In patients with humeral fracture, the axial permissibility was greater than that of the tibia, the periosteal callus size with age was not decreased, but continued to increase (Figure 10). This method makes it possible for patients in the second group over the age of 60 , to treat osteoblasts sensitive to the bone fragment fixation. ${ }^{12,13}$

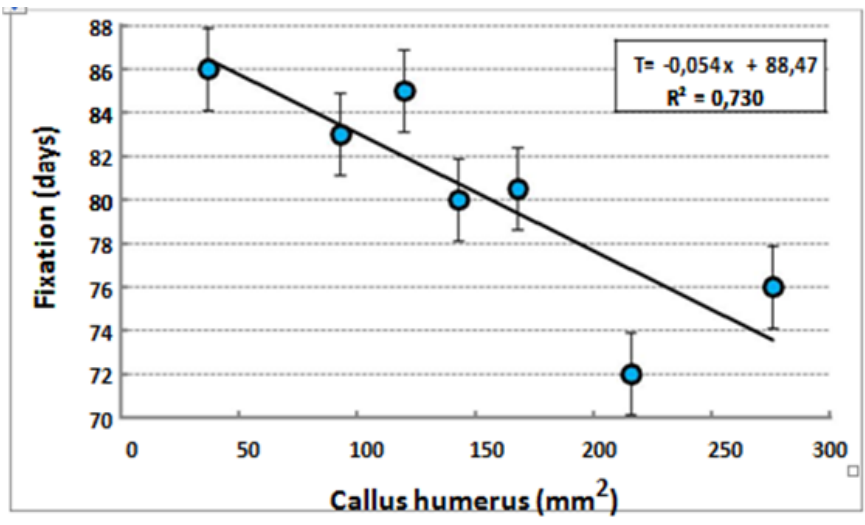

Figure 9 The relationship between periosteal callus values of the humerus and the duration of the fixation period.

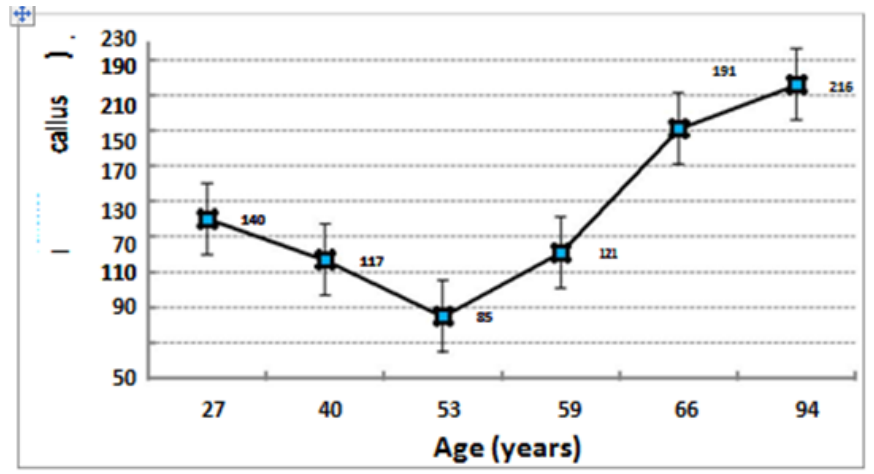

Figure 10 Age dynamics of periosteal callus size of the humerus.

\section{Conclusion}

In the treatment of Ilizarov patients with closed helical fractures of the bones of the leg, when the initial displacement of fragments in width implies the preservation of the integrity of the bone marrow, and micromobility of the ends of fragments less than 50 microns, the periosteal corn does not form. The appearance of periosteal corns is a manifestation of the compensatory response of the body, contributing to the additional fixation of bone fragments in older age groups in an outpatient setting. The formation of this callus contributes to additional fixation of the ends of the fragments and reduce the duration of the period of fixation.

Thus, the study in the clinic confirmed the well-known theoretical propositions that the periosteal callus is formed with insufficient rigidity of fixation of bone fragments. ${ }^{1-3}$ Her education compensates for patients of older age groups involutive reduction in the thickness and strength of bones. There is no doubt that the resulting periosteal coupling is not a consequence of the protrusion of the immature endostal corn, but occurs with long-term preservation of the micro mobility of the bone fragments more than $70 \mu \mathrm{m} / 10 \mathrm{~kg}$.

It was possible to establish that such additional corn formation is necessary when switching to an outpatient treatment regimen, that with increasing age, the need for periosteal fixation increases and, finally, that in the treatment of fractures of leg bones in people over 60 years of age, the reserves for the formation of periosteal corns gradually decrease, and the fixation periods are increasing. 
In the treatment of patients with a fracture of the humerus on an outpatient basis, a compensatory increase in the size of periosteal callus is observed, including in the elderly. As the size of the periosteal callus of the shoulder increases, the duration of the fixation period decreases. Such an age-related increase in the volume of corns and the rigidity of the fixation of fragments leads to the fact that in patients of this group there does not increase with increasing age.

If earlier the increased size of the periosteal callus was considered as a result of a prolonged irritant effect: poor reposition, osteomyolitis or sarcoma ${ }^{8-11}$ then at present, in the treatment conditions of patients according to Ilizarov, it can be viewed as a positive compensatory the reaction of the body, providing additional fixation of fragments and reducing the duration of treatment, in particular, patients of older age groups. ${ }^{14,15}$

\section{Acknowledgments}

None.

\section{Conflicts of interest}

The authors declare there is no conflicts of interest.

\section{References}

1. Lacroix D, Prendergast PJ. A mechanoregulation model for tissue differentiation during fracture healing: analysis of gap size and loading. J Biomech. 2002;35(9):1163-1171.

2. McKinley DW, Chambliss ML. Follow-up radiographs to detect callus formation after fractures. Arch Fam Med. 2000;9(4):373-374.

3. Sarmiento A, Latta LL. Closed functional treatment of fractures. Berlin, Germany: Springer-Verlag. Berlin Heidelberg; 1981:610.
4. Ilizarov GA. Transosseous osteosynthesis. Theoretical and clinical aspects of the regeneration and growth of tissue. Berlin, Germany: Springer-Verlag. Berlin Heidelberg; 1990:799.

5. Schurov VA, Schurov IV. Treatment of fractures of the shin bones according to Ilizarov. Biomechanical, biological and medical aspects. Saarbrücken: Lap Lambert Academic Publishing; 2015:147.

6. Solomin LN. Fundamentals of transosseous osteosynthesis by the device G.A. Ilizarov. SPb, 2005:544.

7. Berquist TH. Authorship Resisted: Part 1. Reparation for Submission to AJR. AJR Am J Roentgenol. 2018;211(4):715-716.

8. Claes LE, Heigele CA, Neidlinger-Wilke C, et al. Effects of mechanical factors on the fracture healing process. Clin Orthop Relat Res. 1998;(355 Suppl):S132-S147.

9. Kenwright J, Goodship AE. Controlled mechanical stimulation in the treatment of tibial fractures. Clin Orthop Relat. 1989;241:36-47.

10. Marsh D. Concepts of fracture union, delayed union, and nonunion. Clin Orthop Relat Res. 1998;(355 Suppl):S22-S30.

11. Yamaji T, Ando K, Wolf S, et al. The effect of micromobility on callus formation. J Orthop Sci. 2001;6(6):571-575.

12. DeForest CA, Anseth KS. Advances in bioactive hydrogels to probe and direct cell fate. Annu Rev Chem Biomol Eng. 2012;3:421-444.

13. Huebsch N, Arany PR, Mao AS, et al. Harnessing traction-mediated manipulation of the cell matrix interface to control stem-cell fate. Nat Mater. 2010;9(6):518-526.

14. Schurov VA. Biomechanics and physiology of bone regenerate. Publishing House Onto-Print; 2018:150.

15. Monahan JJ. Mechanical therapeutics. In: Steinberg GG, Akins CM, Baran DT, editors. Orthopaedics in Primary Care. 2nd ed. Philadelphia, Pa: Lippincott Williams \& Wilkins; 1992:290-315. 